\title{
O que a rede urbana-regional do Brasil tem a dizer sobre o avanço da Covid-19? Ponderações para uma agenda urbana-regional atual e pós-pandemia
}

\author{
What the urban-regional network has to say about Covid-19 expansion? \\ Considerations on an urban-regional agenda to-day and after pandemics \\ Qu'est-ce que le réseau urbain-régional a-t-il à dire sur l'expansion de la \\ Covid-19? \\ ¿Qué tiene que decir la red urbano-regional de Brasil sobre el avance de \\ Covid-19? Consideraciones para una agenda urbano-regional actual y \\ pospandémica
}

\section{Patrícia Silva Gomes e Renata Freitas Carvalho Caldeira}

\section{OpenEdition} Journals

\section{Edição electrónica}

URL: http://journals.openedition.org/espacoeconomia/17912

DOI: 10.4000/espacoeconomia.17912

ISSN: 2317-7837

\section{Editora}

Núcleo de Pesquisa Espaço \& Economia

\section{Refêrencia eletrónica}

Patrícia Silva Gomes e Renata Freitas Carvalho Caldeira, «O que a rede urbana-regional do Brasil tem a dizer sobre o avanço da Covid-19? Ponderações para uma agenda urbana-regional atual e póspandemia», Espaço e Economia [Online], 20 | 2020, posto online no dia 26 dezembro 2020, consultado o 29 janeiro 2021. URL: http://journals.openedition.org/espacoeconomia/17912 ; DOI: https://doi.org/ 10.4000/espacoeconomia.17912

Este documento foi criado de forma automática no dia 29 janeiro 2021.

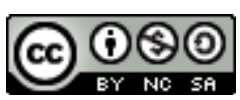

Espaço e Economia - Revista brasileira de geografia econômica est mise à disposition selon les termes de la licence Creative Commons Attribution - Pas d'Utilisation Commerciale - Partage dans les Mêmes Conditions 4.0 International. 


\section{O que a rede urbana-regional do Brasil tem a dizer sobre o avanço da Covid-19? Ponderações para uma agenda urbana-regional atual e pós- pandemia}

What the urban-regional network has to say about Covid-19 expansion?

Considerations on an urban-regional agenda to-day and after pandemics

Qu'est-ce que le réseau urbain-régional a-t-il à dire sur l'expansion de la

Covid-19?

¿Qué tiene que decir la red urbano-regional de Brasil sobre el avance de

Covid-19? Consideraciones para una agenda urbano-regional actual y

pospandémica

Patrícia Silva Gomes e Renata Freitas Carvalho Caldeira

\section{Introdução}

1 Quando este artigo foi escrito em maio de 2020, o novo coronavírus (causador da doença Covid-19) já havia se espalhado por cerca de $70 \%$ da rede urbana nacional e a Organização Mundial da Saúde (OMS) havia declarado a América do Sul e, sobretudo, o Brasil como o novo epicentro da doença no mundo (Chade, 2020), sendo, portanto, a primeira experiência de seu alastramento sobre um país do sul-global. Contraditoriamente, nesse mesmo momento, conquanto a elevação sustentada do número de casos, prolongada por semanas, alguns governos estaduais começavam a tomar as primeiras iniciativas de reabertura da economia. 
2 Consolidada no século XX, a economia global se tornou uma realidade que parecia ser ilimitada, expandindo sem fronteiras, a partir dos fundamentos de mercado, em uma lógica de custos de transação (Thery, 2020). Destaca-se que a interdependência internacional já era conhecida em diversos âmbitos, mas as consequências sanitárias nas proporções trazidas pelo novo coronavírus superaram todas as previsões possíveis. Assim, como primeira experiência pandêmica da era da globalização econômica e social, o novo coronavírus, iniciado na China, na cidade de Wuhan, em 2019, rapidamente se espalhou, seguindo as principais rotas do tráfego aéreo internacional, coincidindo com a geografia dos principais fluxos da economia mundial ao redor do mundo (Echeverría, 2020) - alastrando-se, em efeito cascata, da Ásia para Europa, os Estados Unidos, a América Latina, com casos espalhados em praticamente todo o mundo.

3 E, ao defrontar-se com a sociedade contemporânea da era da neoliberalização, já marcada por barreiras de proteção e individualização dos espaços (carceral and surveillance cities, Soja, 2000; Sennett, 1993), dos corpos (biopolítica, Foucault, 2008) e dos territórios nacionais (Cruz, Forman, 2017; Peck et al., 2012) - desemaranha a crise de uma sociedade na qual os Estados Nacionais impuseram barreiras físicas e sanitárias contra o "vírus estrangeiro". Enquanto a sociedade do norte global e mesmo a classe média brasileira, respaldadas por garantias sociais e patrimônios próprios, puderam cumprir quarentena e se proteger em casa, mas uma ampla parcela de trabalhadores informais, moradores de ruas e demais segmentos desprotegidos ao redor do mundo, sobretudo no sul-global, precisaram se expor para ganhar o alimento que é conquistado por dia de trabalho.

4 Desse modo, ao chegar no país, seguindo esse fluxo global de pessoas e mercadorias, o vírus tem como porta de entrada os principais hubs aeroportuários, atingindo, primeiramente, as grandes metrópoles nacionais - São Paulo, Rio de Janeiro e Brasília e, logo em seguida, as metrópoles estaduais, também bastante conectadas a esses fluxos internacionais de passageiros e mercadorias.

5 A partir daí o vírus se espalha pela rede urbana, pelo contato social, seguindo os deslocamentos intermunicipais, na chamada difusão hierárquica (Xavier et al., 2020), e os intra-urbanos, na chamada difusão por contato (Xavier et al., 2020).

6 A difusão hierárquica está relacionada ao tamanho e à escala de influência funcional da cidade. Assim, em uma primeira onda, o movimento da doença segue do núcleo das grandes metrópoles para a periferia de suas regiões metropolitanas, a partir dos fluxos pendulares que interligam cotidianamente esses espaços. E, em uma segunda onda, a partir do fluxo de pessoas e mercadorias das rodovias e hidrovias, o contágio se espalha para as cidades médias, as chamadas "cidades de beira de rodovias", interligadas funcionalmente ao setor terciário das capitais. No terceiro ciclo, por sua vez, a doença atinge as cidades do interior, cada vez mais afastadas do epicentro inicial.

7 Já a difusão por contato está relacionada ao fato de que para haver a disseminação da doença é preciso que os sujeitos estejam próximos; assim, o agrupamento humano, em densidades altas, sustenta a cadeia de transmissão. Neste sentido, Holanda (2020) observa que importa menos a configuração da cidade, em termos de seu desenho urbano, e mais o comportamento sociocultural da comunidade e a aplicação de políticas de isolamento social. 
Desse modo, ao se completar três meses do primeiro caso confirmado da doença no país - em 26 de fevereiro de 2020, na cidade de São Paulo - o número de casos confirmados no Brasil chega a 363.211 (DataSUS, 2020), até o fechamento deste artigo em 22 de maio de 2020.

9 Este número desconsidera ainda a subnotificação devido à defasagem de testes aplicados no país. Estima-se que a subnotificação é tamanha que possa chegar a um valor 12 a 15 vezes maior do que aquele oficialmente divulgado pelo Governo Federal (Lotufo, 2020). Outrossim, a precisão dos testes realizados é baixa, não havendo como dimensionar ao certo esta quantificação. Soma-se a isso o próprio comportamento da doença, que não gera apenas uma infecção localizada nas vias respiratórias, mas um quadro infeccioso generalizado, que pode afetar diversos órgãos ao mesmo tempo; desse modo, é possível que mesmo casos de mortes cardíacas tenham sido causadas pelo novo coronavírus, sem que estas constem das estatísticas oficiais, pelo não diagnóstico da doença anterior ao falecimento.

10 Ao passo que a Covid-19 acarreta consequências à saúde que variam desde os casos assintomáticos, que podem se tornar, pela ausência de testagem, transmissores potenciais da doença, até aqueles que desenvolvem um quadro infeccioso moderado e grave, e que aí precisarão utilizar uma estrutura hospitalar, geralmente por tempo prolongado, dotada de profissionais e equipamentos de estabilização (em cerca de $20 \%$ dos casos) e leitos de alta complexidade (em cerca de $5 \%$ dos casos), além de possuir importante e heterogêneo percentual de evolução para óbito (Ministério da Saúde, 2020).

11 Desse modo, ao adentrar para o interior da rede urbana, a doença revela um quadro de disparidades inter-regionais e intra-urbanas. Em termos inter-regionais, diferentemente de muitos países, o Brasil teve focos epidêmicos da doença em diversos pontos, coincidindo, inclusive, com os locais já mais fragilizados em termos de precariedade habitacional, ausência de saneamento básico e insuficiência da estrutura de saúde. Em termos intra-urbanos, se o vírus não escolhe a quem contaminar, a sociedade sim, de tal modo que, no país, a pobreza urbana, a informalidade do trabalho, a fragilidade do sistema de saúde, revelaram-se características mais decisivas para as taxas de transmissão e letalidade, do que a predisposição biológica da doença.

12 Revela ainda que não há como promover um efetivo controle da Covid-19 de uma forma isolada - no nível de um município ou mesmo de um estado - visto que as funções estão interligadas. Para que exista uma coordenação entre as medidas adotadas pelos estados e municípios, seria importante o papel protagonista do Governo Federal, em especial dos Ministérios da Saúde e do Desenvolvimento Regional. Entretanto, no Brasil, o isolamento social não foi adotado como política pública Federal, e por isso, não houve o isolamento em conformidade às taxas recomendadas pela OMS (em torno de 70\%).

13 Ademais, para o controle da pandemia faz-se necessária a confiança da população nos especialistas, no poder público, entre os países, além da troca de informação científica confiável e da solidariedade global (Harari, 2020), sendo que a divergência de recomendações entre os entes públicos no país, vem dificultando a adoção de uma estratégia uniformemente respeitada, impossibilitando o combate efetivo ao vírus.

14 Outrossim, diante da ineficácia do governo brasileiro em garantir o auxílio emergencial à população de maior vulnerabilidade e da pouca oferta de créditos aos pequenos 
empresários e profissionais liberais, é ilusória a possibilidade de estes segmentos fazerem o isolamento social.

Frente a esse cenário, o objetivo geral deste artigo é analisar a expansão espaçotemporal do novo coronavírus pela rede urbana nacional (até o recorte temporal da pesquisa), buscando refletir, a partir das características em termos de precariedade habitacional, ausência de saneamento e deficiências da estrutura de saúde, o impacto da doença nas microrregiões do país, além de aventar, por meio do planejamento na escala urbana e regional, possibilidades para a recuperação econômica e social do país no contexto atual e pós-pandemia.

O método de trabalho consistiu na compilação de dados secundários atinentes à: i) casos e óbitos da Covid-19, ii) leitos de UTI disponíveis no Sistema Único de Saúde (SUS) e na rede particular, iii) respiradores mecânicos disponíveis no SUS e na rede particular, iv) polos de saúde de alta, média e baixa complexidade, v) componentes do déficit habitacional mais intrinsecamente ligados aos impactos sanitários e de saúde da Covid-19, vi) população urbana atendida pelas redes públicas de água e esgotamento sanitário.

Os dados atinentes aos casos e óbitos de Covid-19 foram obtidos da base do DataSUS (2020) e abrangem até a data de fechamento desta pesquisa. Os leitos de UTI e respiradores também foram obtidos da base do DataSUS (2020) e se referem a números de abril de 2020. Os dados, desagregados por municípios, foram agregados na escala microrregional para sua melhor interpretação no nível da rede urbana; vale ressaltar, contudo, a limitação destes na representatividade da situação do país, tendo em vista os atrasos de notificações e as retromencionadas subnotificações (mais complexas nos municípios de pequeno porte).

Os dados do déficit habitacional de 2015 foram obtidos pela Fundação João Pinheiro FJP (2018); conforme metodologia de obtenção, a partir da Pesquisa Nacional de Amostra de Domicílios (PNAD), do IBGE, os dados foram agregados por estados e pelas principais regiões metropolitanas do país. Os dados de saneamento, por sua vez, foram obtidos da base do Sistema Nacional de Informações sobre Saneamento - SNIS (2018), desagregados por municípios, mas agregados por microrregiões. Já a regionalização da saúde foi obtida da pesquisa Rede de Influência de Cidades (REGIC) do IBGE (2018).

$\mathrm{O}$ artigo, além desta introdução, se estrutura em três partes: a primeira analisa a expansão espaço-temporal do novo coronavírus pela rede urbana nacional, a segunda, o impacto da doença nas microrregiões brasileiras, considerando suas características sócio-urbanísticas, a terceira, aventa possibilidades para uma agenda urbana-regional de recuperação social e econômica para a crise atual e pós-pandemia, por fim, as conclusões promovem o fechamento do trabalho.

\section{0 que a rede urbano-regional brasileira tem a dizer sobre o avanço espaço-temporal da Covid-19?}

Para a análise do avanço do coronavírus pela rede urbana brasileira, investigou-se o primeiro dia de ocorrência da doença, o número total de casos e de óbitos acumulados por municípios e microrregiões. Pondera-se que a base de dados oficiais do DataSUS (2020) acumula os registrados a partir de 28 de março de 2020 (semana epidemiológica 
13), embora as primeiras ocorrências sejam anteriores a essa data. A figura 1 mostra os casos de Covid-19 e a figura 2 os óbitos por microrregiões.

Figura 1 - Casos de Covid-19 pela rede urbana microrregional.

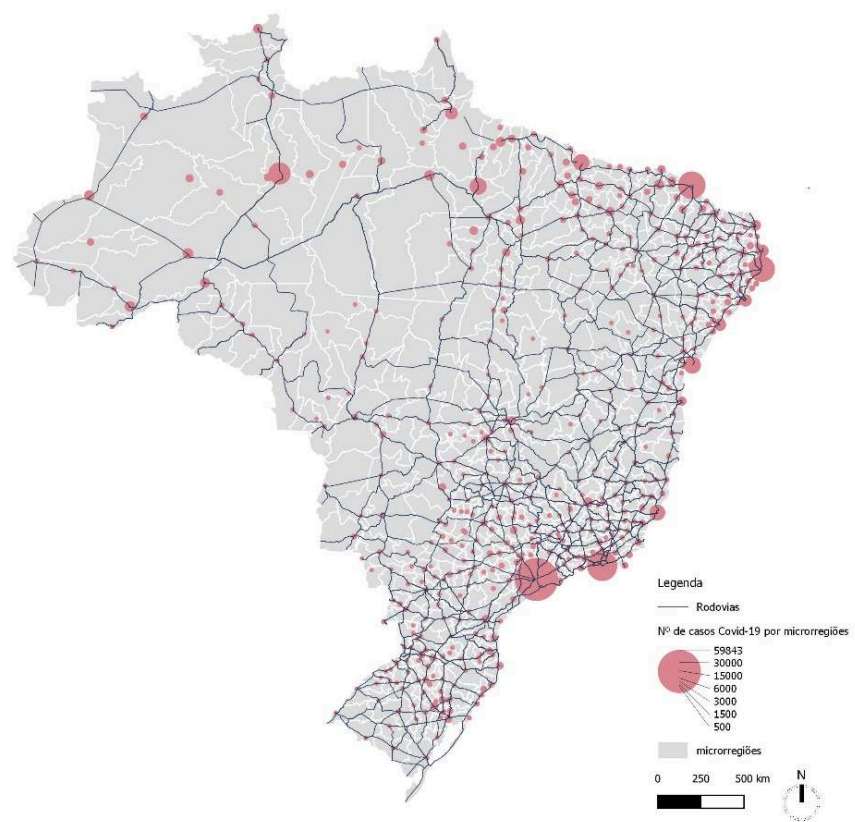

Fonte: Dados do DataSUS (2020), compilados pelas autoras. GaúchaZH (2020), esclarece que a sazonalidade de infecções respiratórias, provocada pelo inverno amazônico, e a maior aglomeração de pessoas, podem ter contribuído para a rápida expansão da doença na capital. 0 alto número de óbitos verificado no estado, o colocou como um dos focos mais graves da doença no mundo (figura 2), sendo que $47,7 \%$ casos estão no interior.

As diferenças regionais são perceptíveis também na forma principal de transporte de pessoas e mercadorias, sendo que na Amazônia isso se deu, majoritariamente, pelo meio fluvial e estradas de terra, ao passo que, no restante do país, por meio de rodovias. As figuras 3 e 4 mostram os casos e óbitos de Covid-19 por municípios. 
Figura 2 - Óbitos de Covid-19 pela rede urbana microrregional.

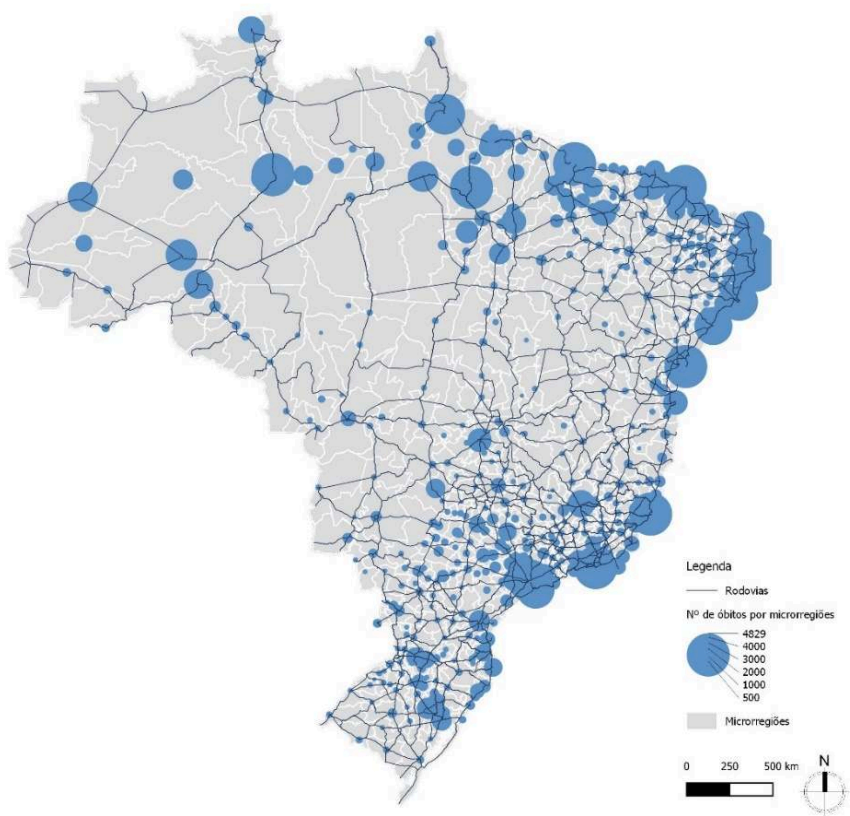

Fonte: Dados do DataSUS (2020) compilados pelas autoras. Largo, Flores de Goiás, Iturama, Jeremoabo e Juara (figura 1). Ao passo que, das microrregiões com mais de 500 casos de Covid-19, 10 estão no Amazonas (Manaus, Lábrea, Tabatinga, Coari, Manacapuru, Tefé, Itacoatiara, São Gabriel da Cachoeira, Eirunepé e Parintins), cinco no Ceará (Sobral, Itapipoca, Acaraú, Quixadá e Russas), sete no Maranhão (São Luís, Imperatriz, Chapadinha, Santa Inés, Pedreiras, Pinheiro e Bacabal), 10 no Pará (Abaetetuba, Tucuruí, Altamira, Belém, Parauapebas, Castanhal, Santarém, Breves, Paragominas e Marabá), quatro na Paraíba (João Pessoa, Campina Grande, Guarabira e Patos) e quatro em Pernambuco (Recife, Caruaru, Vitória de Santo Antão e Goiana).

Em Roraima a microrregião mais afetada é a de Pacaraima (na fronteira com a Venezuela). No Rio de Janeiro as microrregiões mais afetadas, além da capital, são Volta Redonda, Campos dos Goytacazes, Petrópolis e Cabo Frio - e em São Paulo, além da capital, são - Santos, Campinas, Sorocaba, Jundiaí, São José dos Campos, Ribeirão Preto, São José do Rio Preto e Araguaína. 
Figura 3 - Casos de Covid-19 por municípios.

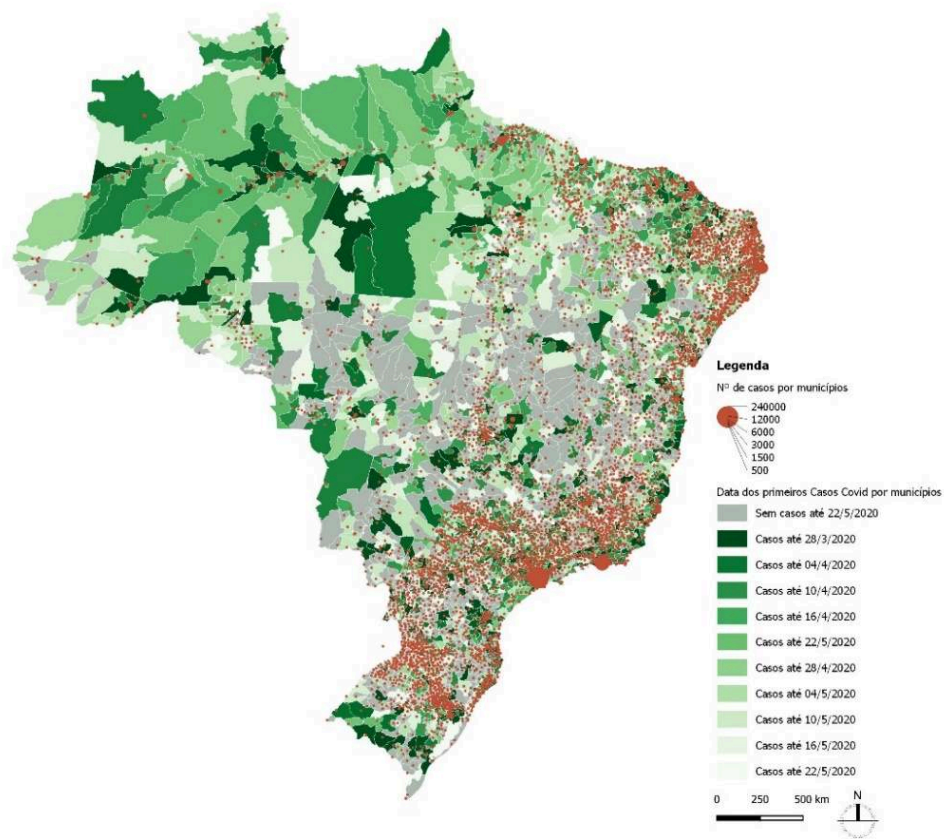

Fonte: Dados do DataSUS (2020) compilados pelas autoras.

Figura 4 - Óbitos por Covid-19 por municípios.

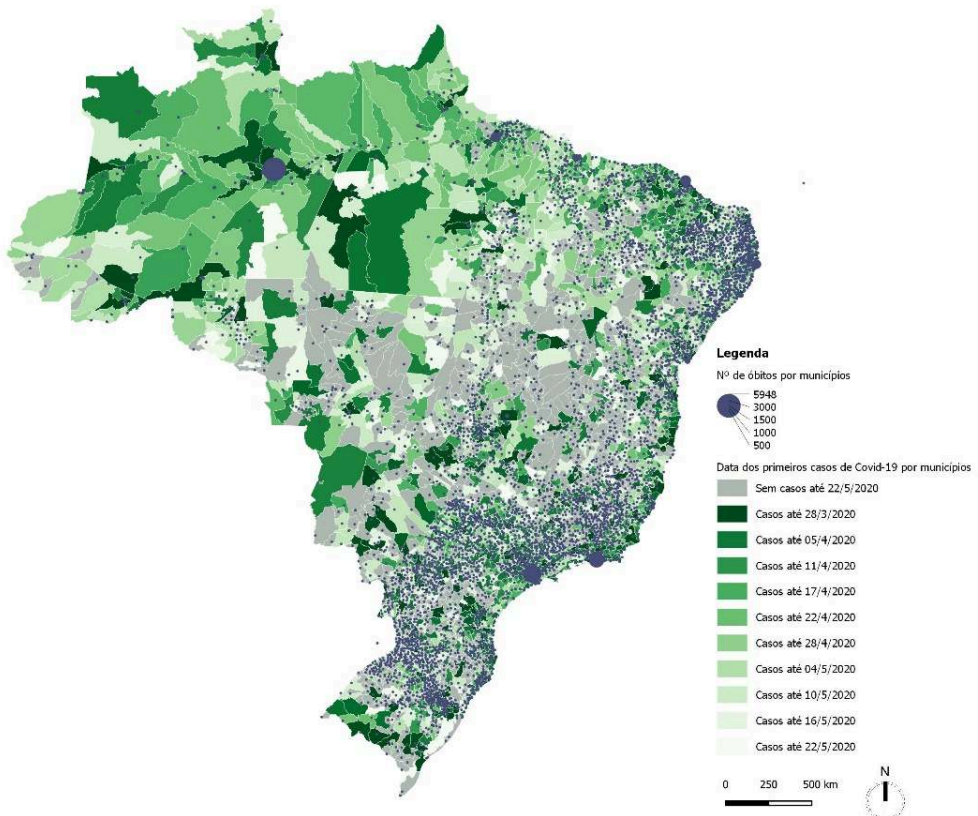

Fonte: Dados do DataSUS (2020) compilados pelas autoras.

27 A disseminação do contágio no interior gera a necessidade de busca por leitos de UTI e serviços especializados, os quais este, na maior parte das vezes, não possui acesso. 0 que gera um ciclo de sobrecarga das cidades com maior complexidade dos serviços de 
saúde, já vista que, além de suprir a necessidade de seus próprios habitantes, estes também serão responsáveis por receber os pacientes dos municípios de menor porte. Neste sentido, faz-se urgente a leitura regional acerca dos sistemas de saúde, para que sejam coordenadas as políticas públicas de contenção da disseminação e de combate ao novo vírus (Xavier et al., 2020).

A pesquisa da REGIC do IBGE (2018), sistematizando a rede de influência das cidades a partir de diversos temas, dentre eles a da oferta de serviços de saúde, busca uma categorização dos polos de baixa, média e alta complexidade em tratamento de saúde no país, conforme pode ser visto nas figuras 5 e 6 .

Figura 5 - Polos de alta complexidade em saúde.

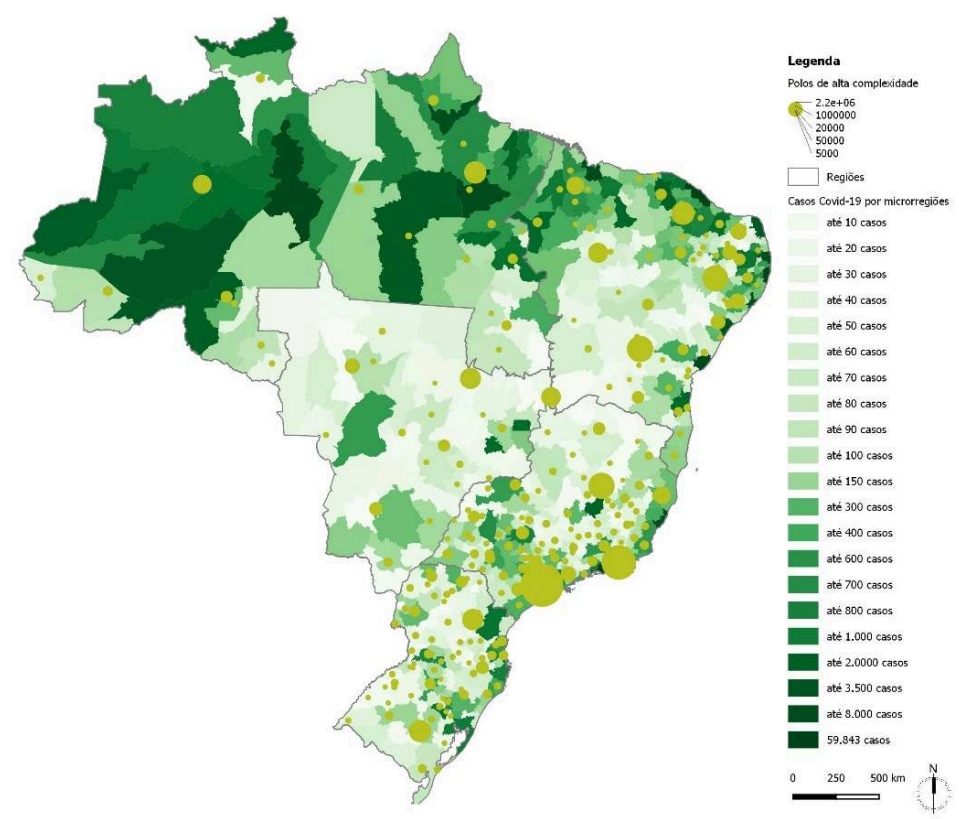

Fonte: DataSUS (2020) compilado pelas autoras.

A situação mais crítica em termos de sobrecarga ao sistema de saúde é a do Amazonas, onde praticamente todas as microrregiões possuem números expressivos de casos, mas há apenas um polo de saúde de alta complexidade - Manaus - gerando sobrecarga neste. Ressalta-se ainda a situação de Pacaraima, com muitos casos, sem uma estrutura de saúde compatível.

O mesmo acontece no Pará, onde quase todas as microrregiões foram afetadas pelo coronavírus, mas há poucos polos de saúde de alta complexidade - Belém, Altamira, Santarém, Tucuruí, Redenção e Marabá. Breves, particularmente, é uma microrregião com muitos casos e sem nenhum centro de saúde de alta complexidade próximo. 0 mesmo ocorre ainda no Maranhão, onde praticamente todas as microrregiões estão impactadas e há poucos centros de alta complexidade - São Luís, Imperatriz, Matões do Norte e Pinheiro. 
Figura 6 - Polos de baixa e média complexidade.

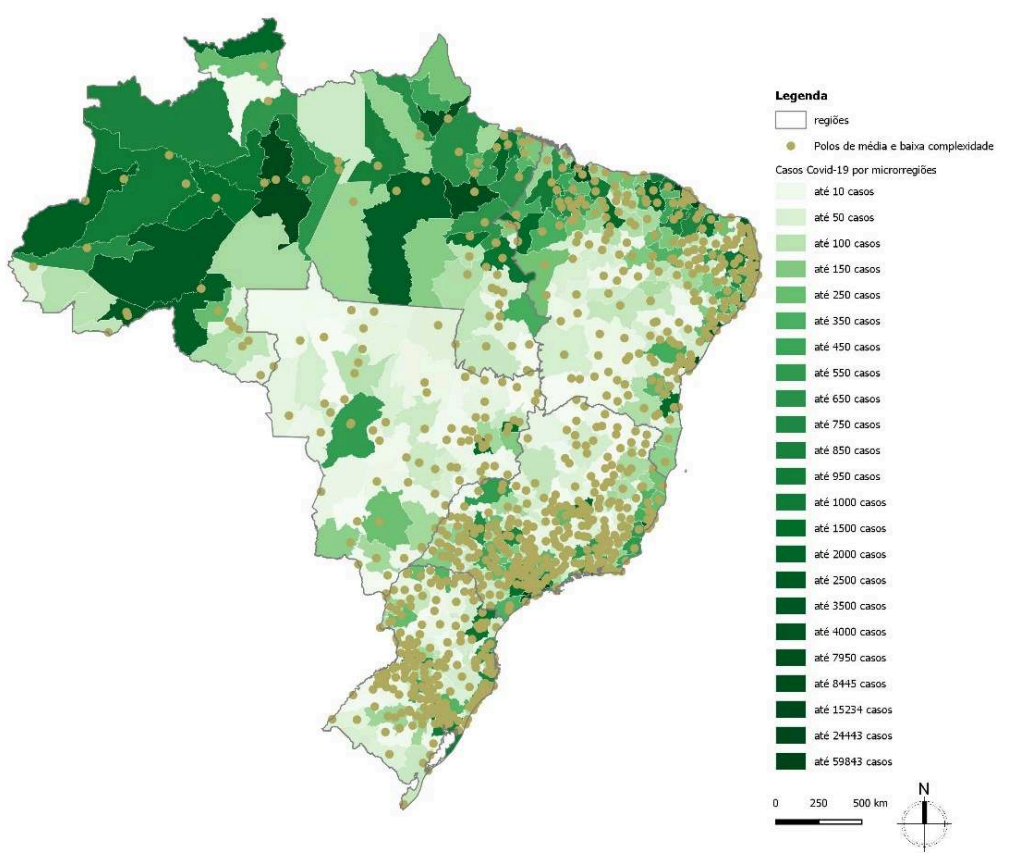

Fonte: DataSUS (2020) compilado pelas autoras.

31 Outrossim, o Cadastro Nacional dos Estabelecimentos de Saúde (CNES) do DataSUS (2020) fornece o quantitativo de respiradores mecânicos e leitos de UTI disponíveis por municípios brasileiros (figuras 8 e 9). Pondera-se, contudo, as limitações desses dados em representar a conjuntura situacional, especialmente no caso dos respiradores, tendo em vista as constantes aquisições emergenciais e a condição de pleno funcionamento.

Esses dados reforçam a complexidade da situação do Amazonas, onde, das 10 microrregiões mais afetadas, muitas delas abrangendo territórios indígenas, o número de respiradores mecânicos e leitos de UTI é, respectivamente, de 1021 e 3875 em Manaus, 2 e 194 em Lábrea, 13 e 256 em Tabatinga, 3 e 188 em Coari, 0 e 132 em Manacapuru, 5 e 321 em Tefé, 3 e 237 em Itacoatiara, 8 e 139 em São Gabriel da Cachoeira e 12 e 297 em Parintins. 
Figura 7 - Respiradores por microrregiões.

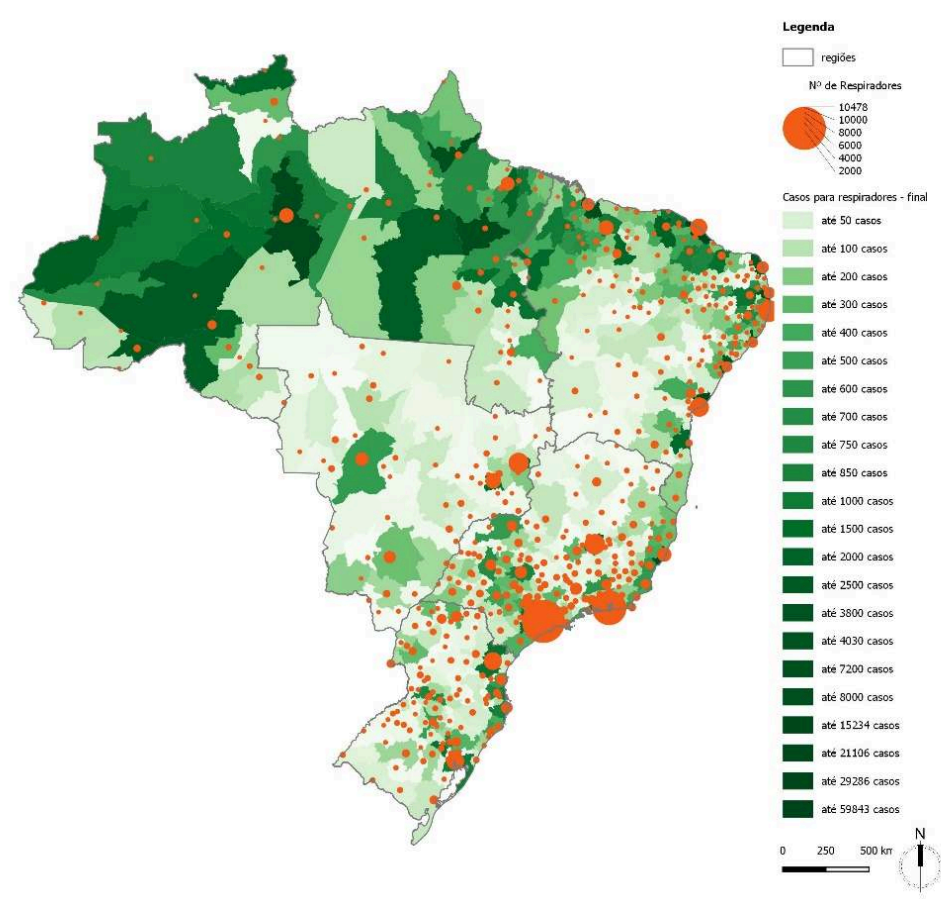

Fonte: DATASUS (2020) compilado pelas autoras.

Figura 8 - Respiradores por microrregiões.

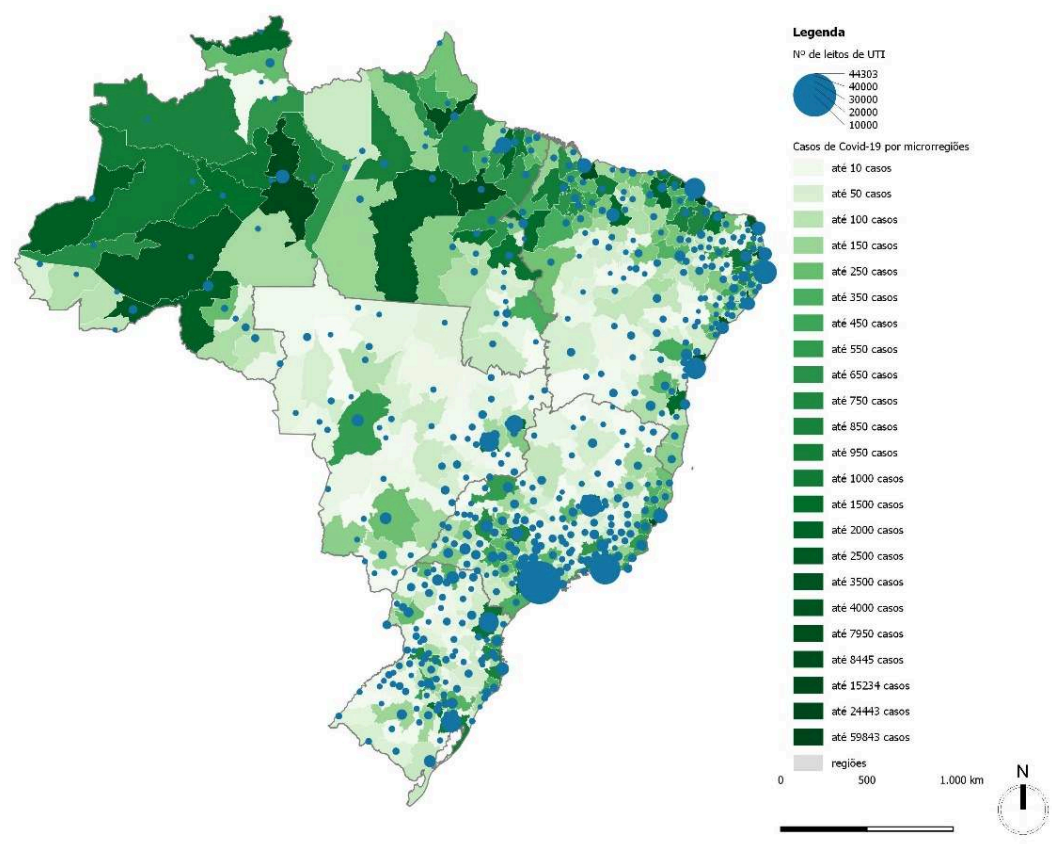

Fonte: DATASUS (2020) compilado pelas autoras.

A situação é igualmente crítica no Pará, onde as microrregiões mais afetadas também possuem uma baixa disponibilidade de respiradores e leitos de UTI, o que é o caso de Abaetetuba, Tucuruí, Altamira, Belém, Parauapebas, Castanhal, Santarém, Breves, 
Paragominas e Marabá. Além das microrregiões de Sobral, Itapipoca, Acaraú, Quixadá e Russas, no estado do Ceará, e São Luís, Imperatriz, Chapadinha, Santa Inês, Pinheiro e Bacabal, no Maranhão.

Vale ressaltar que muitos desses municípios, considerados polos de saúde de baixa e média complexidade (figura 6), acabam também por receber a demanda dos municípios menores que, ao circularem pela rede urbana, podem ocasionar a difusão hierárquica do vírus. Agrava esse quadro a baixa e lenta criação de hospitais de campanha e de espaços de triagem em comunidades carentes e tradicionais, capazes de testar e evitar o avanço da doença especialmente em áreas densas e precárias.

\section{0 que a precariedade habitacional e de saneamento têm a dizer sobre os impactos da Covid-19 sobre a rede urbana-regional?}

35 O déficit habitacional do país (FJP, 2020), conquanto os desafios metodológicos intrínsecos para sua obtenção, é dividido em duas grandes categorias - quantitativo, isto é, quando é necessário incrementar o estoque de novas habitações, e qualitativo, isto é, quando não é preciso a construção de novas habitações, mas sim a qualificação das já existentes. As figuras 9 e 10 mostram o déficit habitacional quali-quantitativo absoluto e relativo do país.

Vale ressaltar que os quatro componentes do déficit quantitativo - habitação precária, coabitação familiar, ônus excessivo com aluguel e adensamento excessivo em imóveis não-próprios - estão diretamente relacionados aos impactos sanitários e econômicos da Covid-19. As regiões Norte e Nordeste têm a maior participação relativa neste déficit quantitativo (12,6 e 11\%), enquanto as regiões Centro-Oeste, Sudeste e Sul participam com 10,0, 8,4 e 7,0\% respectivamente. Em termos absolutos, os estados com maior déficit quantitativo são - São Paulo (1,33 milhões), Minas Gerais (575.498), Bahia (461.700), Rio de Janeiro (460.785), Maranhão (392.308), Pará (314.643) e Ceará (302.623).

A precariedade habitacional, que retrata as moradias em condições inadequadas de habitabilidade, é maior, em termos absolutos, nos estados do Maranhão (241.278), Pará (98.607), Bahia (83.640), São Paulo (77.325) e Ceará (73.568).

Já a coabitação familiar, que retrata os lares com mais de uma família convivente, podendo corresponder, inclusive, a situações de convivência de grupos etários distintos, por exemplo, avós morando com netos, é mais expressiva nos estados de São Paulo (326.522), Minas Gerais (209.544), Bahia (193.087) e Pará (133.109). Outro componente do déficit quantitativo que retrata a situação de adensamento das moradias, o adensamento excessivo em imóveis alugados, dentre eles o aluguel de cômodos em cortiços por pessoas e famílias distintas, é mais expressivo nos estados de São Paulo (131.873), Rio de Janeiro (33.779), Minas Gerais (16.928), Ceará (14.759), Pará (14.364), Pernambuco (13.520) e Amazonas (13.020). 


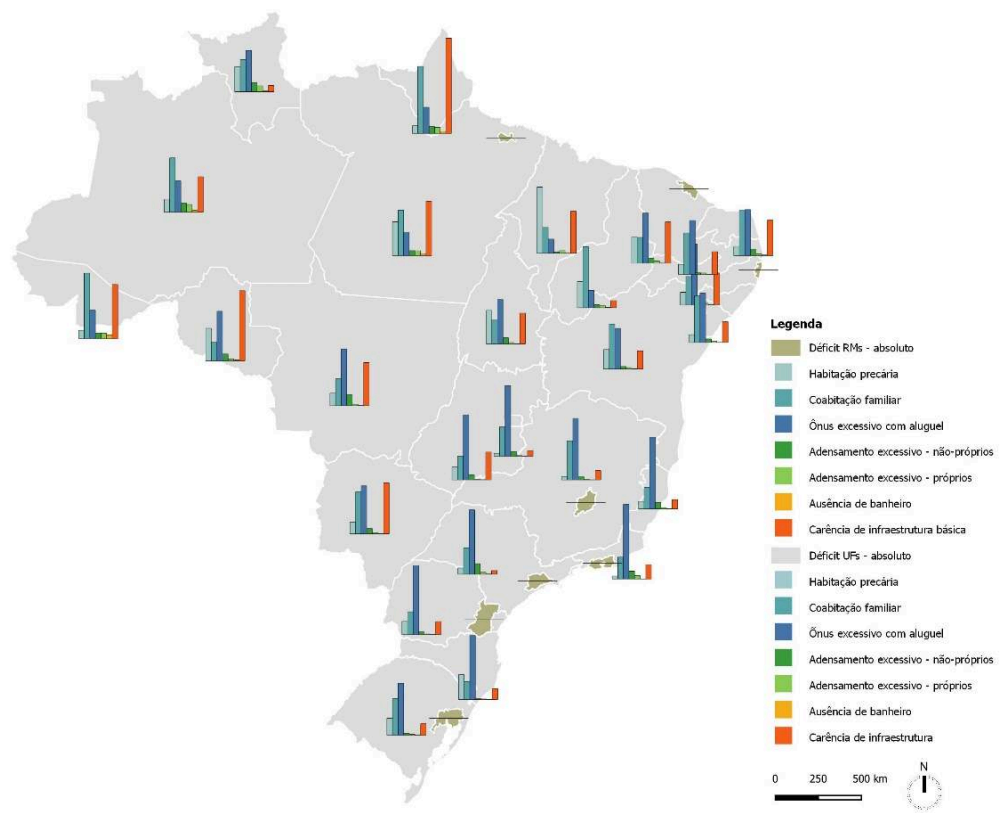

Fonte: FJP (2018) compilado pelas autoras. o item que mais pesa na composição do déficit quantitativo, o que é o caso, por exemplo, do Amazonas (50,4\%), Piauí (56,8\%), Acre (60,8\%) e Amapá (62,3\%). Assim, percebe-se que os estados mais afetados pela Covid-19 também se caracterizam por números expressivos de déficit quantitativo que, particularmente, podem ter contribuído para a rápida transmissão da doença, como é o caso do Maranhão, Ceará, Amazonas, Pará e Maranhão.

Ora, se a contaminação é maior quanto menor a capacidade da comunidade em manter o distanciamento, é ilusório pensar que em um país onde a coabitação e a habitação precária são uma realidade a ordem de manter-se em casa por tempo indeterminado seria de fato medida aplicável.

Particularmente no Rio de Janeiro e em São Paulo além da possível contribuição desses componentes de precariedade e adensamento das moradias na elevação do número de casos, destaca-se o maior peso percentual do aluguel no orçamento familiar, apontando também para um expressivo impacto econômico atual e pós-pandemia, que pode refletir no aumento dos despejos e das ocupações, conquanto a decisão recente de suspensão dos despejos por inadimplência até 30 de outubro de 2020 (Projeto de Lei $n^{\circ}$ $1.179 / 2020)$.

O ônus excessivo com aluguel chega a 801.317 habitações de São Paulo, 320.288 do Rio de Janeiro, 330.090 de Minas Gerais e 186.389 do Paraná. Em termos relativos, o ônus excessivo com aluguel corresponde a 59,9\% do déficit habitacional de São Paulo, 69,5\% do Rio de Janeiro, $64,3 \%$ do Paraná, $46,7 \%$ do Ceará, 59,5\% de Santa Catarina, $66,8 \%$ do Espírito Santo, 52,8\% do Mato Grosso, 46,2\% de Rondônia, 41,25\% de Tocantins e 38,3\% de Roraima. 

Ceará (792.738), Rio de Janeiro (782.355), Pernambuco (731.636) e Bahia (635.275). Proporcionalmente, ela é maior nos estados do Norte - Amapá (88,5\%), Rondônia (65,3\%), Pará $(50,6 \%)$ e Acre $(50,3 \%)$.

Já o adensamento excessivo em imóveis próprios é mais expressivo, em termos absolutos, em São Paulo (279.851), Rio de Janeiro (182.091), Pará (74.519) e Amazonas (62.490).

Outros estados ainda dividem a importância entre a coabitação familiar e o ônus excessivo com aluguel na composição do déficit quantitativo, como é, respectivamente, o caso de Minas Gerais (36,4 e 57,4\%), Bahia (41,8 e 37,7\%), Pernambuco (26,6 e 56,8\%), Goiás (22,3 e 60,7\%), Rio Grande do Sul (33,9 e 48,4\%), Distrito Federal (27,2 e 65,7\%), Paraíba (38,7 e 50,3\%) e Rio Grande Norte ( 42,5 e $42,8 \%)$.

mais expressivo são a de São Paulo (639.839), Rio Janeiro (340.083), Belo Horizonte (158.839), Fortaleza (147.111), Recife (130.142), Salvador (139.173) e Belém (101.835).

Em termos relativos, os componentes que mais pesam no déficit quantitativo das RMs são o ônus excessivo com aluguel, que chega a 58,3\% na RM de São Paulo, 66,1\% na RM do Rio de Janeiro, 57,7\% na RM de Fortaleza e 62,9\% na RM de Curitiba. Já a coabitação familiar e o ônus excessivo com aluguel são, respectivamente, os itens mais importantes da composição do déficit quantitativo nas RMs de Belo Horizonte (39,7 e $53,8 \%$ ), Salvador (39,9 e 53,1\%), Porto Alegre (30,4 e 50,0\%) e Recife (31,9 e 63,0\%).

O déficit habitacional qualitativo, por sua vez, também possui uma intrínseca correspondência com os impactos sanitários da Covid-19, retratados em componentes como carência de infraestrutura básica, adensamento excessivo de imóveis próprios (quando há mais de três pessoas dormindo em um mesmo cômodo) e ausência de banheiro.

Componente de enorme peso no país como um todo, a carência de infraestrutura é particularmente mais expressiva, em termos absolutos, nos estados do Pará (848.158), Proporcionalmente, o adensamento excessivo em imóveis próprios é significativo no Amazonas (7,1\%), Amapá $(5,6 \%)$ e Roraima (5,5\%). Esses dados corroboram que o adensamento das construções, sobretudo no caso do Amazonas, pode ter contribuído para a rápida propagação da doença. 


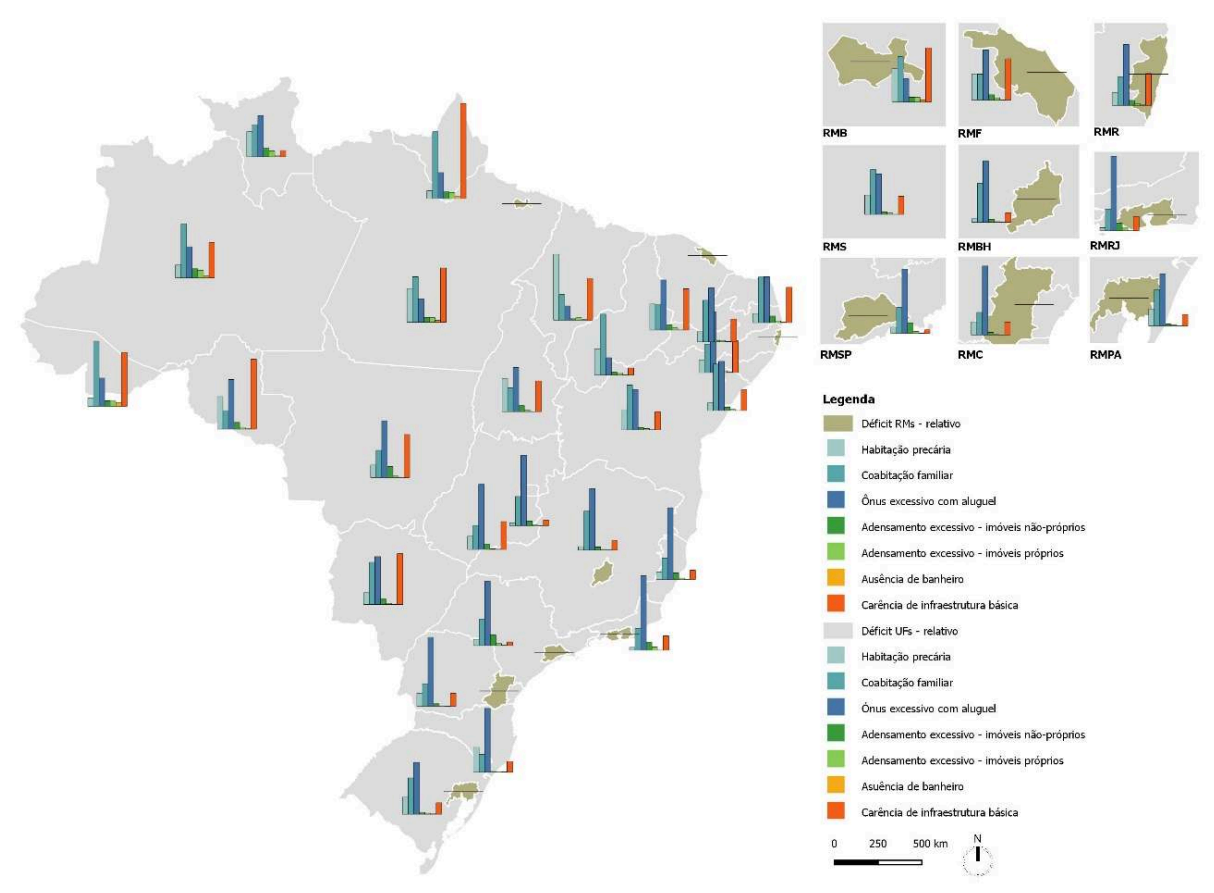

Fonte: FJP (2018) compilado pelas autoras.

Item básico de higiene para a prevenção e controle da Covid-19, as moradias sem banheiro acumulam números de 38.872 em São Paulo, 31.813 no Pará, 15.296 no Amazonas e 12.128 em Minas Gerais. Em termos proporcionais, a ausência de banheiros é mais representativa na composição do déficit qualitativo do Acre $(3,3 \%)$, Pará $(1,9 \%)$, Amapá (1,9\%) e Amazonas (1,7\%).

Em relação às RMs monitoradas, o déficit absoluto por carência de infraestrutura básica é maior no Rio de Janeiro (531.736), Recife (445.464), Fortaleza (412.216) e São Paulo (255.901); já em termos proporcionais, destacam-se as situações de Fortaleza (36,2\%), Recife $(35,9 \%)$ e Belém $(31,1)$ - todas essas focos importantes de disseminação do novo coronavírus no país.

O adensamento excessivo em imóveis próprios é maior, em termos absolutos, nas RMs de São Paulo (207.526) e Rio de Janeiro (151.834); já, em termos relativos, ele constitui 4,8\% da composição do déficit qualitativo da RM de Belém, 3,5\% da RM do Rio de Janeiro e 2,9\% da RM de São Paulo, corroborando o potencial de propagação da doença na periferia dessas metrópoles.

53 A ausência de banheiro, em termos absolutos, atinge 19.355 moradias da RM de São Paulo e 10.172 da de Belém - números maiores, inclusive, do que aqueles encontrados em muitos estados brasileiros. Em termos relativos, a ausência de banheiro é significativa na RM de Belém (31,1\%) e de Recife (35,9\%).

O SNIS é a maior pesquisa sobre saneamento básico no país, conquanto sua limitação metodológica em utilizar a autodeclaração das informações pelas concessionárias locais e abranger apenas os serviços prestados pela rede pública, desconsiderando os sistemas individuais e alternativos de tratamento e distribuição de água e esgotamento. 
Figura 11 - Situação de abastecimento de água e esgotamento em áreas urbanas por microrregiões.

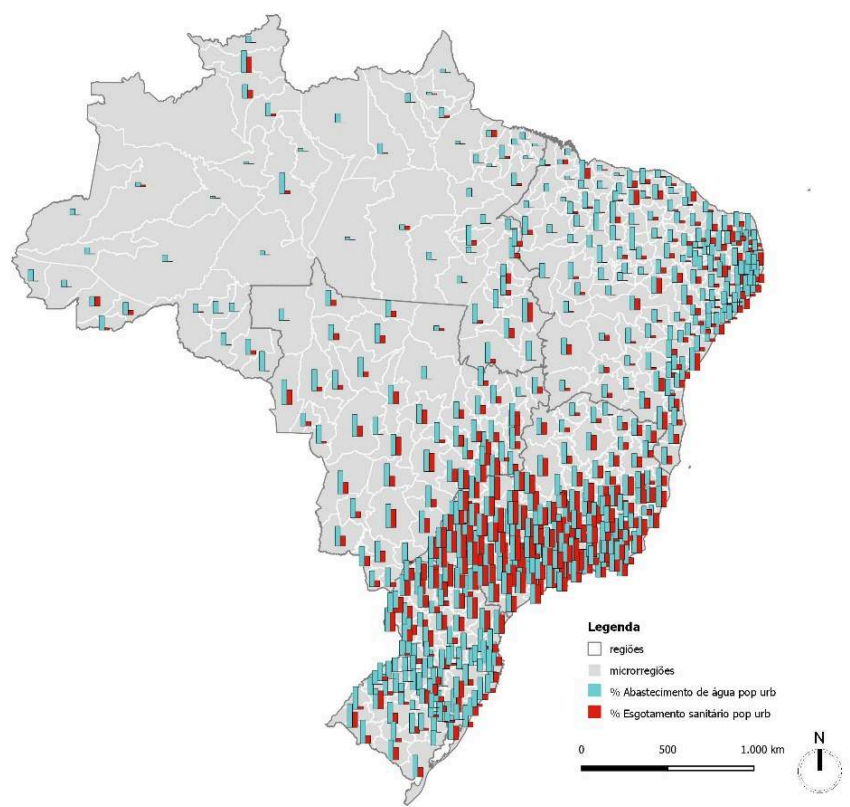

Fonte: SNIS (2018) compilado pelas autoras

Conforme dados do SNIS (2018), o sistema público de água resulta em um índice de atendimento de $57,1 \%$ no Norte, $74,2 \%$ no Nordeste, $91,0 \%$ no Sudeste e $90,2 \%$ no Sul e $89,0 \%$ no Centro-Oeste, enquanto o índice geral de água do Brasil é de 83,6\% (figura 11). Assim, a falta de acesso à água tratada dificulta a adoção de uma medida fundamental para o controle da doença - a higienização das mãos.

Já o sistema de esgotamento possui um índice de coleta de esgotamento em torno de $83,6 \%$, mas o índice de tratamento é precário no país como um todo $(46,3 \%)$ e particularmente baixo nas regiões Norte (10,5\%) e Nordeste (28,0\%), enquanto fica em $79,2 \%$ no Sudeste, $45,2 \%$ no Sul e $52,9 \%$ no Centro-oeste (figura 11 ).

Heller et al. (2020) e vários outros autores ao redor do mundo apontam para os riscos de transmissão feco-oral da Covid-19 pelo lançamento de efluentes sanitários in natura a céu aberto e no leito dos rios, o que é particularmente grave nas áreas precárias mais adensadas.

8 Vale ressaltar que várias microrregiões com grande ocorrência de casos da Covid-19 também se caracterizam pelos baixos percentuais de atendimento por rede pública de água, sobretudo no Pará (Abaetetuba, Bragança, Breves) e Maranhão (Tutóia, Viana e Pinheiro). Também vários casos se espalharam por regiões críticas em termos de ausência do esgotamento sanitário, como é o caso do Amazonas (Lábrea, Tabatinga, Coari, Manacapuru, Itacoatiara, São Gabriel da Cachoeira, Parintins, Manicoré e Tefé) e Acre (Tarauacá, Cruzeiro do Sul, Brasiléia).

Vale ressaltar que esse quadro precário do saneamento, fica particularmente crônico frente ao esvaziamento da pasta no Governo Federal (com a transferência das funções, antes de responsabilidade majoritária do extinto Ministério das Cidades, para o Ministério do Desenvolvimento Regional) e a significativa redução dos aportes de 
financiamento ao setor. Os investimentos em saneamento passaram de $\mathrm{R} \$ 11,4$ bilhões, em 2014 (Oliveira et al., 2016), para 835,5 milhões, em 2019, e com previsões de gasto de apenas 661 milhões em 2020 (Arcoverde, 2019). Soma-se a isso as desastrosas consequências socioespaciais (em termos de efetiva universalização rumo aos territórios e comunidades mais vulneráveis) e ambientais (em termos de efetiva conservação da dinâmica hídrica, despoluição de bacias e diminuição redução/ reutilização/reciclagem dos resíduos sólidos) que a abertura para a privatização dos serviços de saneamento, conforme o Projeto de Lei n 3.261/2019, poderão provocar.

Vale ressaltar que o próprio setor produtivo, evidentemente pela lógica da redução dos custos diretos e indiretos de produção e produtividade, reconhece os entraves que a ausência de saneamento básico pode provocar ao país.

61 Para uma efetiva reversão das carências de saneamento na rede urbana do país, faz-se necessária a abertura de linhas de financiamento para os projetos de sistemas descentralizados em áreas isoladas e comunidades não atendidas pela rede pública, com a adoção de soluções sustentáveis e de baixo custo, envolvendo a assessoria técnica de entidades e universidades, assim como para a instalação de banheiros, que compõe, como se viu, frágil componente do déficit habitacional.

\section{Quais as possibilidades para uma agenda de planejamento urbano-regional atual e pós-pandemia?}

O vírus chega ao Brasil em um momento de tímida recuperação econômica, precarização do trabalho (com alta taxa de desemprego e ampla parcela de trabalhadores na informalidade ${ }^{1}$ ), desmonte das proteções sociais, aumento da pobreza e das desigualdades sociais, retorno do país ao mapa da fome. Choca ainda com um país que já vinha perdendo a capacidade de articulação federal do planejamento urbano, sobretudo após a extinção do Ministério das Cidades e a transferência das funções para o Ministério do Desenvolvimento Regional.

A agenda do planejamento regional, que nem mesmo chegou a emplacar, conforme o Decreto Federal $\mathrm{n}^{0}$ 9810/2019, promulgado quase quatro anos depois da apresentação formal da Política Nacional de Desenvolvimento Regional (PNDR), se torna particularmente fragilizada frente à relativa desindustrialização do Sudeste (Cano, 2012), comoditização da economia pela produção de grãos no cerrado (centro-oeste e MATOPIBA $^{2}$ ), e mineração (Minas Gerais e Norte), além dos baixos investimentos federais em infraestrutura setorial e social, que pudessem auxiliar na reversão das disparidades inter-regionais.

A própria PNDR continuou sem instrumentos substantivos de execução, do ponto de vista orçamentário, institucional ou organizacional, enquanto o fundo constitucional de desenvolvimento regional, que deveria constituir a maior fonte de financiamento ao setor, com crédito para as pequenas e médias empresas e a agricultura familiar, vem sendo utilizada, não obstante, dissociada desta, não promovendo, assim, a reversão das desigualdades.

65 A adoção de medidas coordenadas, sólidas e holísticas de planejamento tem-se mostrado a saída mais rápida para a crise, mas, no Brasil, a possibilidade delas se estilhaça no vórtice da crise política provocada pelo governo federal. Assim, se a provocativa parada técnica da sociedade e da economia poderia representar uma 
chance para rever prioridades e começar de novo, a conjuntura política do país não permite vislumbrar, dentro da institucionalidade, uma saída efetiva.

Fora dela, de baixo para cima, uma agenda popular - plural, propositiva e, sobretudo, mais aderente à realidade do território - tem iluminado as ações setoriais mais efetivas para a saída da crise, embora abafada pelo esfacelamento dos canais participativos e pela falta de financiamento para os projetos sociais. Vale ressaltar que os próprios movimentos sociais organizados (Frente Brasil Popular, Frente Povo Sem Medo, Central Única das Favelas) apresentaram propostas para a crise do novo coronavírus.

Frente a isso, e a partir dos caminhos percorridos por esse artigo, levanta-se aqui quatro possibilidades para uma agenda urbana e regional para atual e pós conjuntura da crise do coronavírus. Vale ponderar, contudo, que elas não têm a pretensão de abranger a totalidade de particularidades sociais e territoriais subjacentes aos temas; a mobilidade urbana, por exemplo, cara ao planejamento urbano-regional e com várias peculiaridades no atual contexto epidêmico, não será aqui nuançada.

68 A primeira delas é a necessidade de uma recuperação das economias urbanas a partir de uma efetiva inversão de prioridades, pois, se o governo não privilegiar os pequenos comércios e os setores informais - mais drasticamente prejudicados pela parada técnica - não tem como se falar em saída auto-sustentável para a crise. A título de exemplo, do montante de 1 trilhão e 500 bilhões de reais liberados, em março de 2020, pelo Governo Federal para o enfrentamento da crise, 1 trilhão e 200 bilhões foram disponibilizados pelo Banco Central para o socorro do sistema financeiro e às grandes corporações (Roubicek, 2020).

69 Enquanto isso, vários pequenos negócios estão agonizando no país pela falta de solvência (por caixa ou endividamento) para acesso ao crédito e/ou pela falta de crédito com juros compatíveis, gerando não apenas a falência dessas empresas, mas também, em cascata, o desemprego; o que pode se prolongar no contexto pós-pandemia pela possível desaceleração do consumo, em decorrência da redução geral das rendas e mesmo com o congelamento dos salários no setor público. Soma-se a isso o fato de vários estabelecimentos comerciais do país serem alugados, aumentando, ainda mais, as despesas de custeio sem a efetiva entrada de capital.

70 Cavalcante e Campolina (2020), destacam, a partir dos dados da Relação Anual de Informações Sociais - RAIS (2018), que as micro e pequenas empresas perfazem $98 \%$ do total de estabelecimentos do país e $40 \%$ da massa salarial mensal do setor privado. A par disso, o Governo Federal não tem garantido um conjunto de medidas aderentes à heterogeneidade de condições desses setores - profissionais liberais, agricultura familiar, comércio local - dificultado, assim, a recuperação econômica. Ademais, propostas do tipo corte de salários podem representar um desastre econômico. Segundo a PNAD do $1^{\circledR}$ trimestre do IBGE (2020), quase 5 milhões de pessoas já perderam o emprego entre fevereiro e abril deste ano.

71 Já os setores informais, que respondem por espantosos $50 \%$ da economia, vêm passando por grande perda da renda nesse tempo de pandemia. Boa parte desses trabalhadores (sem inclusão cadastral e digital) têm tido dificuldade em acessar o auxílio emergencial. A articulação da economia popular à economia dos setores público e formal, inserindo-a na cadeia de produção e consumo, poderia ser uma alternativa para salvaguardar esse setor no contexto atual e pós-pandemia. Ressalta-se ainda a necessidade de 
continuidade, também no médio prazo, de algumas políticas de segurança alimentar e proteção contra despejos, para esses setores.

72 A segunda delas é a necessidade de uma política habitacional que alcance ganho de escala e atuação multisetorial no enfrentamento do imenso problema da necessidade de regularização plena dos assentamentos precários do país. Vale ressaltar que, nos últimos anos, as políticas de regularização fundiária plena além de reduzirem, perderam qualidade a partir do novo marco legal da Lei Federal $n^{\circ} 13.465 / 2017$. Isso porque, ao eleger um tipo de regularização pensada a partir da titulação dos imóveis, antes da qualificação plena do bairro, como tradicionalmente ocorreu, ainda que sem escala no Brasil, a Lei acaba por desperdiçar oportunidades de investimentos holísticos na colocação da infraestrutura básica.

73 Ao passo que o impacto do ônus excessivo com aluguel, componente que assumiu a dianteira do déficit habitacional brasileiro nos últimos anos, deve ser ainda maior nesse contexto atual e pós-pandemia, acarretando também o aumento do número de ocupações. Desse modo, a adoção de uma ampla política de proteção do aluguel - com aluguel social, estímulos aos locadores particulares que direcionarem os imóveis para fins sociais e o uso do estoque vazio, em retrofit, para moradia dos segmentos vulneráveis - faz-se necessária. Assim como é importante manter a garantia do direito de posse, para que não ocorram despejos em massa de pessoas em condições de instabilidade financeira.

74 Ressalta-se também a importância de uma política habitacional direcionada à população em situação de rua, com a aprovação de serviços de moradia social, além da ampliação de políticas públicas assistenciais que possuam caráter emergencial, haja vista que esta população acumula diversos agravantes em sua condição de vida.

75 Além, certamente, das políticas de melhorias habitacionais, conforme a Lei de Assessoria Técnica (Lei Federal no 11.888/2008), dirigidas, sobretudo, para os lares sem banheiro e com adensamento excessivo de cômodos. Vale ressaltar que a falta de canais de financiamento públicos para projetos apresentados pelas entidades e/ou em parceria com as universidades poderia representar, paralelamente a ação governamental, um ganho de escala das ações.

76 A terceira delas é a necessidade do aumento dos investimentos no setor de saneamento básico no país. Acredita-se que os investimentos no setor, além de atacar um imenso problema socioambiental do país, poderia representar uma alternativa de alavancagem da economia, a partir do setor da construção civil. Ademais, os investimentos em saneamento representam importante externalidade positiva para o sistema de saúde.

77 A quarta delas é a condução de uma política regional, que priorize reverter os impactos de saúde e econômicos nas regiões mais afetadas pela epidemia. Do ponto de vista interregional, a recuperação econômica pode ser desigual, tendo em vista as particularidades as quais cada região foi impactada - o Centro-oeste, por exemplo, que tem participação importante do agronegócio na estrutura produtiva, não parou, ao contrário, bateu recorde de safra, podendo ter menores dificuldades de recuperação econômica alavancada por esse setor; ao passo que o Norte e o Nordeste foram mais impactados; o Sudeste também sofreu forte impacto, pelo peso do terciário, do serviços do terciário superior e pela queda da produção industrial, sobretudo de bens duráveis; vale ressaltar, contudo, que a própria PNAD do $1^{\circ}$ trimestre mostrou que os setores industriais ligados à alimentação e higiene tiveram alta. 
78 A pandemia pegou um sistema industrial brasileiro altamente comprometido pela falta de competitividade frente à produção chinesa, a tal modo que não conseguiu disponibilizar nem mesmo máscaras cirúrgicas ou respiradores mecânicos para a sociedade. Algumas indústrias, contudo, conseguiram fazer a "reconversão produtiva" em suas plantas e adaptar a produção para os novos produtos demandados pela crise álcool em gel, máscaras, aventais, equipamentos de proteção individuais, etc.

Acredita-se que uma economia de crise sanitária deva se prolongar mesmo após a pandemia, com a maior demanda da sociedade por setores de saúde, adaptação de equipamentos para biossegurança, produtos de higiene, fármacos, equipamentos médicos. Assim, estruturar arranjos produtivos locais que possam engrenar as economias regionais a partir desses setores pode representar uma saída para a crise.

80 A rede urbana do interior também mostrou os impactos de saúde e econômicos, de tal modo que várias Prefeituras Municipais, sem leitos de UTI ou respiradores, e sem capacidade de investimento pelo desenho fiscal do pacto federativo e Lei de Responsabilidade Fiscal, acabaram por transferir seus problemas para os municípios maiores na rede urbana. Assim, reconhecer a importância dos pequenos empreendimentos do interior, manter programas de renda mínima e estímulos à agricultura familiar nesses territórios, parece ser uma possibilidade importante de ação. Vale ressaltar, também, que, consoante aos objetivos da PNDR, é salutar ampliar os investimentos em saúde e saneamento nas microrregiões mais críticas.

81 É preciso atenuar também os impactos ocorridos nas principais RMs e aglomerações urbanas do país, visto que esses locais vêm sofrendo, sobretudo, com a sobrecarga da estrutura hospitalar advinda de outros municípios, além dos impactos econômicos da parada técnica da economia. Cavalcante e Campolina (2020) observam, a partir dos dados da RAIS (2018), que as grandes cidades - Rio de Janeiro, Belo Horizonte, Porto Alegre, Curitiba, Campinas, Salvador, Recife e Fortaleza - concentram $40 \%$ do emprego no setor privado e $54 \%$ da massa salarial, assim, particularmente, faz-se necessário fortalecer os pequenos negócios e os segmentos informais, sobretudo nas periferias dessas grandes cidades.

\section{Conclusões}

O artigo mostrou como a hierarquia funcional das cidades contribuiu para a difusão da Covid-19 pela rede urbana-regional do país. A doença vem se caracterizando pela ocorrência de vários focos epidêmicos espaço-temporais no país, atingindo, inclusive, precocemente, cidades menos integradas aos circuitos superiores da economia, como é o caso do interior do Norte e Nordeste. Nesse espectro, as características em termos de precariedade habitacional e de saneamento, podem ter contribuído para a alta transmissividade da doença nesses espaços, o que foi agravado pelas condições desiguais da estrutura de saúde em absorver os impactos da doença no interior da rede urbana.

Dentre as possibilidades para uma agenda urbana-regional de recuperação social e econômica frente a atual e pós-pandemia, o artigo levantou quatro possibilidades: a ativação das economias urbanas, sobretudo nos pequenos negócios nas capitais e na rede urbana mais capilarizada pelo interior, investimentos em política habitacional, sobretudo em ações que priorizem o aluguel, a proteção contra despejos e a reversão do 
déficit qualitativo, além de uma política saneamento (entendida também como uma medida de ativação econômica). Por fim, o resgate de uma política regional faz-se urgente e inafastável, visto que a crise do coronavírus escancara a relação entre os municípios das microrregiões e assim, é inequívoca a necessidade da articulação de políticas de desenvolvimento nesta escala.

\section{BIBLIOGRAFIA}

AQUINO, V; MONTEIRO, N. Brasil confirma primeiro caso da doença. Disponível em: < https:// www.saude.gov.br/noticias/agencia-saude/46435-brasil-confirma-primeiro-caso-de-novocoronavirus>. Acessado em: 22 de maio de 2020.

ARCOVERDE, L. Orçamento do governo federal prevê queda de $21 \%$ nos recursos para saneamento básico em 2020. Portal de notícias G1. Disponível em: <https://g1.globo.com/ economia/noticia/2019/09/05/orcamento-do-governo-federal-preve-queda-de-21percent-nosrecursos-para-saneamento-basico-em-2020.ghtml>. Acessado em: 22 de maio de 2020.

BARRUCHO, L. Brasil é um dos países que menos realiza testes para covid-19, abaixo de Cuba e Chile. BBC News Brasil. Disponível em: <https://www.bbc.com/portuguese/ internacional-52383539>. Acessado em: 9 de maio de 2020.

CAVAlCANTE, A.; CAMPOLINA, B. Nota Técnica - Desafios e Propostas para Enfrentamento do

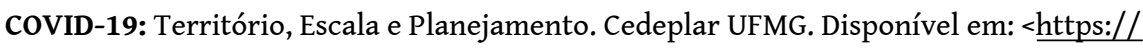
www.cedeplar.ufmg.br/noticias/1232-nota-tecnica-desafios-e-propostas-para-enfrentamentodo-covid-19-territorio-escala-e-planejamento>. Acessado em: 19 de maio de 2020.

CHADE, J. OMS diz que América do Sul é novo epicentro da pandemia e Brasil preocupa. Portal UOL. <https://noticias.uol.com.br/colunas/jamil-chade/2020/05/22/oms-am-do-sul-e-umnovo-epicentro-e-nao-recomenda-uso-amplo-de-cloroquina.htm>. Acesso em: 22 de maio de 2020.

COELHO, F. C. et al. Assessing the potential impacts of COVID-19 in Brazil: Mobility, morbidity and impact to the health system. < http://bibliotecadigital.fgv.br/dspace/handle/10438/28941>. Acessado em: 23 março de 2020.

CRUZ, T. FORMAN, F. Unwalling citizenship. Architecture Against a Developer Presidency. The Avery Review, Issue 21. January 20, 2017.

DATA-SUS. Cadernos de Informação de Saúde. 2020. < https://datasus.saude.gov.br/>. Acesso em: 22 de maio de 2020.

DOLZAN, M. Monitor acompanha taxas de isolamento social no Brasil. Jornal Folha de São Paulo. <https://www.estadao.com.br/infograficos/saude,monitor-acompanha-taxas-deisolamento-social-no-brasil,1093828>. Acesso em: 22 de maio de 2020.

ECHEVERRÍA, J. O coronavírus e a globalização. Jornal Folha de São Paulo. Disponível em: <https://www1.folha.uol.com.br/mundo/2020/04/o-coronavirus-e-a-globalizacao.shtml>. Acessado em: 23 de maio de 2020.

FOUCAULT, M. Nascimento da Biopolítica. São Paulo: Martins Fontes, 2008. 


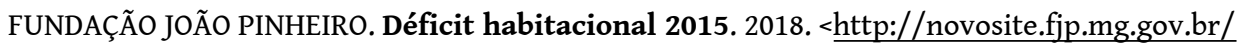
deficit-habitacional-no-brasil/>. Acessado em: 10 de maio de 2020.

GARCIA, D. Informalidade supera 50\% em 11 estados do país, diz IBGE: Taxa tem maior nível desde 2016 e atinge 41,1\%. Disponível em: <https://www1.folha.uol.com.br/mercado/2020/02/ informalidade-atinge-recorde-em-19-estados-e-no-df-diz-ibge.shtml>. Acessado em: 24 de maio de 2020 .

HARARI, Y. Na batalha contra o coronavírus, faltam líderes à humanidade. Tradução Odorico Leal. Companhia das Letras, 2020.

HELLER, L; MOTA, C. R.; GRECO, DB. COVID-19 faecal-oral transmission: Are we asking the right questions? Science of The Total Environment, v.729, 2020. Disponível em: <https:// www.sciencedirect.com/science/article/pii/S0048969720324360?via\%3Dihub>. Acessado em: 18 de maio de 2020.

HOLANDA, F. A cidade pós pandemia. Urbanidades. Disponível em: <https://www.youtube.com/ watch?v=k7nBz6uFzeE>. Acessado em: 18 de maio de 2020.

IBGE. PNAD Contínua do 1ํo trimestre de 2020. Disponível em: <https://www.ibge.gov.br/ estatisticas/sociais/trabalho/9171-pesquisa-nacional-por-amostra-de-domicilios-continuamensal.html?=\&t=o-que-e>. Acessado em: 19 de maio de 2020.

IBGE. Regiões de influência das cidades 2018. Disponível em: <https://www.ibge.gov.br/ geociencias/organizacao-do-territorio/redes-e-fluxos-geograficos/15798-regioes-de- influenciadas-cidades.html?=\&t=o-que-e>. Acessado em: 19 de maio de 2020.

LOTUFO, P. Com poucos testes de covid-19, mortes por todas as causas viram dado crucial. Publicado em 08 de maio de 2020. Disponível em: <https://jornal.usp.br/atualidades/calculo-dopico-da-covid-19-deve-levar-em-conta-quantidade-de-mortes/>. Acessado em: 18 de maio de 2020.

MACHADO, L. Coronavírus: a rodovia federal que 'levou' a Covid-19 para o interior de Pernambuco. BBC News Brasil. São Paulo, 2020. Disponível em: <https://www.bbc.com/ portuguese/brasil-52332235>. Acessado em: 20 de maio de 2020.

MADEIRO, C. Por que o Ceará é o epicentro do coronavírus no Nordeste. Portal de notícias UOL. Disponível em: <https://noticias.uol.com.br/saude/ultimas-noticias/redacao/2020/03/27/ por-que-o-ceara-e-o-epicentro-do-coronavirus-no-nordeste.htm>. Acessado em: 19 de maio de 2020.

MELLO-THÉRY, N.; THÉRY, H . A geopolítica do COVID-19. Revista Espaço e Economia [Online], Publicado em 08 abril 2020. Disponível em: <http://journals.openedition.org/espacoeconomia/ 11224>. Acessado em: 19 de maio de 2020.

MINISTÉRIO DA SAÚDE. Diretrizes para diagnóstico e tratamento de Covid-19. 2020.

Disponível em: <https://sbim.org.br/images/files/notas-tecnicas/ddt-covid-19-200407.pdf>. Acesso em: 19 de maio de 2020.

OLIVEIRA, F. (org). Efetividade dos investimentos em saneamento no país. FGV: Centro de Estudos em Regulação e Infraestrutura. São Paulo: FGV- CERI, 2016.

PECK, J.; THEODORE, N.; BRENNER, N. Mal-estar no pós-neoliberalismo. Novos estudos CEBRAP, no 92, São Paulo Mar. 2012.

ROUBICEK, M. Qual foi o quadro da renda dos brasileiros nos estados em 2019. Nexo Jornal. Publicado em: 01 de março de 2020. Disponível em: <https://www.nexojornal.com.br/expresso/ 
2020/03/01/Qual-foi-o-quadro-da-renda-dos-brasileiros-nos-estados-em-2019>. Acessado em 22 de maio de 2020.

ROUBICEK, M. Qual o leque de respostas do governo para a crise econômica. Nexo Jornal. Disponível em: <https://www.nexojornal.com.br/expresso/2020/04/06/Qual-o-leque-derespostas-do-governo-para-a-crise-econ\%C3\%B4mica>. Acessado em 22 de maio de 2020.

SENNET, R. o declínio do homem público - As tiranias da intimidade. São Paulo: Companhia das Letras, 1993.

SOJA, E. W. Postmetropolis: critical studies of cities and regions. Oxford: Malden, Mass.: Blackwell Publishers, 2000.

TELLES, E. Tendências atuais da pandemia de Covid-19: Interiorização e aceleração da transmissão em alguns estados. Revista Fitos. Publicada em 27 de abril de 2020. Disponível em: <http://revistafitos.far.fiocruz.br/fitos/index.php/noticias/tendencias-atuais-da-pandemia-decovid-19-interiorizacao-e-aceleracao-da-transmissao-em-alguns-estados>. Acessado em 23 de maio de 2020.

XAVIER, D.; et al. Nota técnica. Monitora COVID-19. FIOCRUZ Publicada em 02 de abril de 2020. Disponível em < $<$ https://bigdata-covid19.icict.fiocruz.br/nota_tecnica_1.pdf $>$. Acessado em 20 de maio de 2020.

\section{NOTAS}

1. Em 11 estados brasileiros a informalidade chega a mais de $50 \%$ da população trabalhadora (Garcia, 2020), sendo apontado, em fevereiro de 2020, pelo IBGE, que dentre 1,8 milhão de vagas, 1 milhão é de trabalhadores informais. O Distrito Federal, destacado pela alta concentração de servidores públicos, é única das unidades federativas que possui renda média maior que $R \$ 2.000$, ficando em $R \$ 2.685$. A distância para o segundo colocado, São Paulo, é de mais de R\$ 700 reais. No extremo oposto, dois estados possuem renda menor que $\mathrm{R} \$ 800$, sendo esses Alagoas e Maranhão (Roubicek, 2020).

2. Acrônimo formado pelos estados do Maranhão, Tocantins, Piauí e Bahia, para caracterizar a nova e indômita frente de do agronegócio no cerrado brasileiro.

\section{RESUMOS}

O artigo busca analisar a expansão espaço-temporal do novo coronavírus pela rede urbana nacional, bem como refletir, a partir de aspectos como precariedade habitacional, ausência de saneamento básico e deficiências da estrutura de saúde, sobre o impacto da Covid-19 nas diversas microrregiões do país, mostrando como as diferenças inter-regionais e intra-urbanas contribuem para potencializar os efeitos da doença. A partir daí aventam-se possibilidades ao planejamento urbano-regional, à ativação das economias urbanas e às políticas habitacional e de saneamento como saídas para enfrentamento da crise atual e pós-pandemia. 
The article seeks to analyze the space-temporal expansion of the new coronavirus by the Brazilian urban network, as well to reflect, based on the characteristics in terms of housing precariousness, lack of basic sanitation and deficiencies in the health structure, the impact of the Covid-19 in the country's micro-regions, showing how interregional and intra-urban differences contribute to potentiate the effects of the disease. From there, suggest some possibilities for the urban-regional planning, for the activation of urban economies, heavily affected, and housing and sanitation policies, as ways to face the current and post-pandemic crisis.

Cet article analyse l'expansion du nouveau coronavirus à travers le réseau urbain national afin de montrer comment la précarité des logements, l'absence d'assainissement et les fragilités des structures de santé publique contribuent à potentialiser les effets de la maladie. A la fin, on indique comment les politiques d'aménagement liées à l'habitation et à l'assainissement seront importants pour réactiver les économies urbaines tant aujourd'hui qu'après la crise.

Este artículo analiza la expansión del nuevo coronavirus a través de la red urbana nacional con el fin de mostrar cómo la precariedad de la vivienda, la falta de saneamiento y la fragilidad de las estructuras de salud pública ayudan a potenciar los efectos de la enfermedad. Al final, se indica cómo las políticas de desarrollo relacionadas con la vivienda y el saneamiento serán importantes para reactivar las economías urbanas tanto ahora como después de la crisis.

\section{ÍNDICE}

Mots-clés: Covid-19 et le réseau urbain brésilien, politique du logement, assainissement, économie urbaine et régionale, planification urbaine et régionale.

Palavras-chave: Covid-19 e rede urbana brasileira, política habitacional, saneamento, economia urbana e regional, planejamento urbano e regional.

Keywords: Covid-19 and the Brazilian urban network, housing policy, sanitation, urban and regional economics, urban and regional planning

Palabras claves: Covid-19 y la red urbana brasileña, política de vivienda, saneamiento, economía urbana y regional, planificación urbana y regional.

\section{AUTORES}

\section{PATRÍCIA SILVA GOMES}

Dra. em Arquitetura e Urbanismo pela UFMG, Professora Adjunta da Faculdade de Arquitetura e Urbanismo da Universidade de Brasília (FAU-UnB). Email: patriciasgomes@unb.br

\section{RENATA FREITAS CARVALHO CALDEIRA}

Bacharel em Direito pelo Centro Universitário de Brasília (2018). Graduanda em Arquitetura e Urbanismo pela Universidade de Brasília. Email: renatafccaldeira@gmail.com 